\title{
Load Frequency Controller Based on Particle Swarm Optimization for Isolated Microgird System
}

\author{
Tarek Hassan Mohamed \\ Faculty of Energy Engineering \\ Aswan University, Egypt \\ tarekhie@aswu.edu.eg \\ Mahmoud M. Hussein \\ Faculty of Energy Engineering \\ Aswan University, Egypt \\ mahmoud.hussein@aswu.edu.eg
}

\author{
Hussein Abubakr* \\ Faculty of Energy Engineering \\ Aswan University, Egypt \\ husseinabubakr@energy.aswu.edu.eg \\ G. Shabib \\ Faculty of Energy Engineering \\ Aswan University, Egypt \\ Higher Institute of Engineering and Technology \\ King Marriot, Egypt \\ gabershabib@gmail.com
}

\begin{abstract}
Load frequency control is a major issue in power systems operation. The performance of adaptive particle swarm optimization (PSO), coefficient diagram method (CDM) and conventional integral (PI) controller are compared for an isolated single area non re-heated turbine microgrid with using both of electric vehicle (EVs) and heat pump water heaters (HPs) as controllable loads. The dynamic response of LFC is studied using MATLAB 2017a Simulink package to validate the effectiveness of the proposed scheme. The results indicated that the system with PSO technique has better convergence and robustness than CDM in face of uncertainties due to load perturbations.
\end{abstract}

Keywords - Load Frequency Control (LFC), Particle Swarm Optimization (PSO), Coefficient Diagram Method (CDM), Electric Vehicle(EV), Heat Pump(HP).

\section{INTRODUCTION}

Frequency is a key stability criterion in power system operation. At any area increasing load is a vast problem for power generation plants due to increase in demand for power. So, making balance between generation and demand is the operating principle of load frequency control (LFC) [1].

A system load change causes a change in the speed of Turbine-Generator rotor system. For stabilizing the system frequency, a primary control action of the governor control has been initiated. To regulate system perturbation in the frequency of the supply to set nominal value is the primary objective of automatic generation control (AGC). So, supplementary control action is required to restore frequency to nominal value and it regulates the interchange of power system for the reliability and quality of power supply [1-4]. This problem is generally referred to as load frequency control (LFC). The control is dependent on the governor speed regulation $(\mathrm{R})$ and the integral controller gain (Ki).
This control technique is found to be easy in implementation but generally gives large frequency deviations. Optimal control techniques based on feedback controllers have been proposed to achieve better performance [5-7] but it was found that some information about the states are difficult to be known completely.

To overcome these drawbacks and to solve the load frequency control problem effectively, neural network, Fuzzy logic, and optimization algorithms as intelligent techniques are proposed by many authors [8-16]. Another various control strategy has been proposed and investigated by several researchers for LFC design of power systems for obtaining faster response and robustness against load perturbations like a MPC controller and can be obtained in [17].

Particle swarm optimization technique (PSO) has been introduced by Kennedy and Eberhart [18, 19]. It is initialized by a population of random solution for position and velocity. The potential solution called particles. Each particle keeps track of its coordinates in the search space which are associated with the optimum candidate solution (best fitness). The PSO technique can generate a high quality solution within shorter calculation time and stable convergence characteristic than other stochastic methods [20].

In [21], a coefficient diagram method is a new algebraic method for robust controller design of smart loads such as plug- in hybrid electric vehicle (EV) and heat pump (HP) for frequency controller in an isolated microgrid powered by photovoltaic system and diesel generator. This strategy is applied to a polynomial loop in the parameter space.

In this study, Adaptive particle swarm algorithm (PSO) is used to determine the integral controller (Ki) according to the system dynamics to guarantee the best result as well as to ensure the robustness of the proposed controller. In this 
simulation study, an isolated single area power system is chosen and adaptive load frequency control of this system is made by PSO. The overshoots and settling times with the proposed PSO-I controller are better than the outputs of the conventional (I) controllers tuned by CDM technique.

This paper is organized as follows: Section 2 describes the dynamics of the proposed system. Section $\mathbf{3}$ an overview on PSO and CDM techniques. Section $\mathbf{4}$ a frequency control based on adaptive PSO (System configuration). Section 5 Simulation results. Finally, the conclusion is in Section 6.

\section{SYSTEM DYNAMICS}

In this section, a simplified frequency response model for a single area microgrid with an aggregated generator unit is described in [22]. The state variable model is derived by means of block diagram for uncontrolled isolated microgrid shown in fig. 1. with the speed changer position is taken as control parameter.

$\dot{X}(t)=A x(t)+B u(t)+C d(t)$

where, $A$ is the system matrix, $B$ is input distribution matrix, $C$ is input disturbance distribution matrix. Also, $\dot{X}(t)$ is state vector, $u(t)$ is control vector and $d(t)$ is disturbancevector of load change.

$$
\begin{aligned}
& x(t)=\left[\begin{array}{lll}
\Delta f & \Delta p_{g} & \Delta p_{v}
\end{array}\right]^{T} \\
& u(t)=\left[\Delta p_{c}\right] \\
& d(t)=\left[\Delta p_{d}\right] \\
& y(t)=\left[\begin{array}{lll}
1 & 0 & 0
\end{array}\right] \text { where } \mathrm{y}=\Delta f
\end{aligned}
$$

For the single area non-reheat thermal system considered in this study, the conventional fixed Proportional integral (PI) controller was utilized with the following structure:

$$
G_{c}=K_{p}+\frac{K i}{S}
$$

Where $K_{p}$ is proportional gain, $K_{i}$ and $K_{d}$ are integral and derivative time constants, respectively.

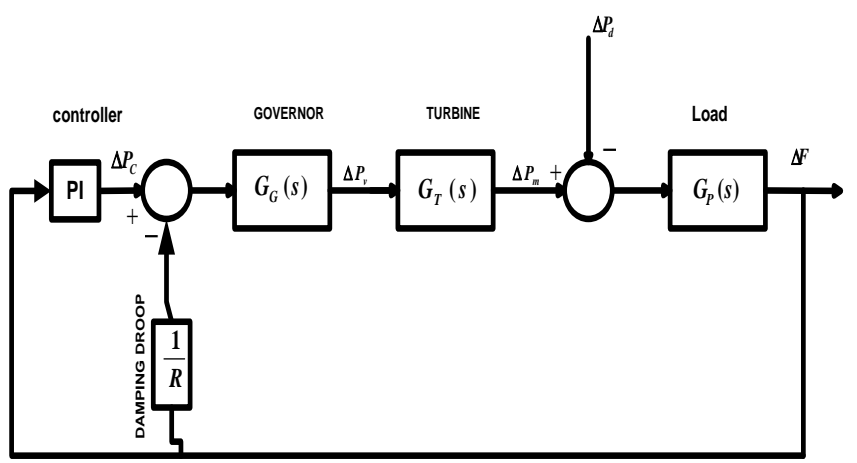

Fig. 1. Block diagram of single area non-reheated turbine without controller.

\section{An OVERVIEW: CDM and PSO TECHNIQUES.}

\section{1. Coefficient Diagram Method (CDM)}

Coefficient Diagram Method (CDM) is an algebraic design approach-based polynomials and polynomial matrices. CDM is based on the stability index and equivalent time constant so it can be considered as generalized PID because of complexity of its controller than PID.

The CDM is fairly new and not well-known, but its basic principle has been known in industry and in control community for more than 40 years with successful application in servo control, steel mill drives control, gas turbine control, and spacecraft attitude control [23].

The standard block diagram of the CDM design for a single input single output (SISO) linear time invariant system is shown in fig. 2.

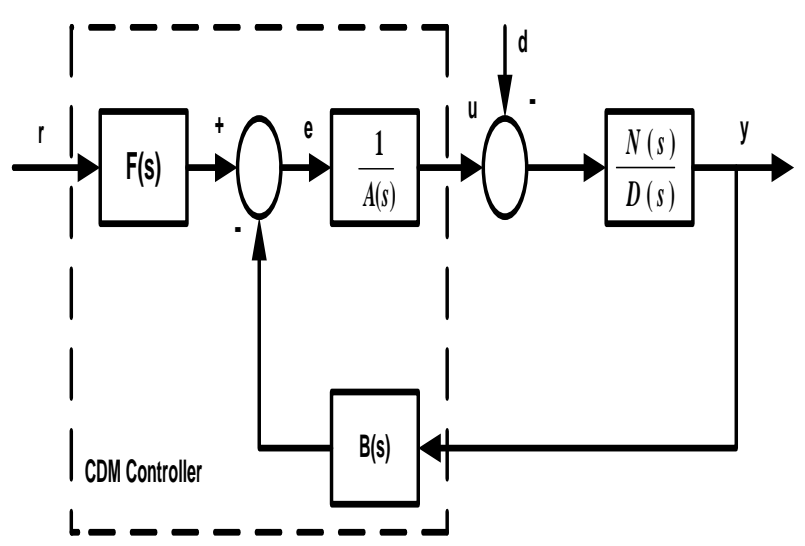

Fig. 2. Block diagram of CDM closed loop control system.

Here, $\mathrm{y}$ is the output, $\mathrm{r}$ is the reference input, $\mathrm{u}$ is the control and $d$ is the external disturbance signal. $N(s)$ and $D(s)$ are the numerator and denominator polynomials of the transfer function of the plant respectively. Also, $\mathrm{A}(\mathrm{s})$ is the forward numerator polynomial, $\mathrm{F}(\mathrm{s})$ and $\mathrm{B}(\mathrm{s})$ are considered as reference numerator and feedback numerator polynomials of the controller respectively [21].

The output of the closed loop control system can be described as: -

$y=\frac{N(s) F(s)}{P(s)} r+\frac{A(s) N(s)}{P(s)} d$

where, $\mathrm{P}(\mathrm{s})$ is considered as the characteristic polynomial of the closed-loop system and is defined by

$P(s)=A(s) D(s)+B(s) N(s)$
$A(s)=\sum_{i=0}^{P} l_{i} s^{i} \quad$ and $\quad B(s)=\sum_{i=0}^{q} k_{i} s^{i}$ 


\section{2. Particle Swarm Optimization (PSO)}

PSO is one of the optimizations and evolutionary computation techniques. It has been found to be robust in solving problems featuring nonlinearity and nondifferentiability, and high dimensionality through adaptation, which is derived from the social-psychological theory. The features of the method are as follows:

1. The method is developed from research on swarm such as fish schooling and bird flocking.

2. It is based on a simple concept. Therefore, the computation time is short and requires few memories [24].

3. It was originally developed for nonlinear optimization problems with continuous variables. It is easily expanded to treat a problem with discrete variables. According to the research results for birds flocking are finding food by flocking.

PSO is basically developed through simulation of bird flocking in two-dimension space. The position of each particle is represented by $\mathrm{XY}$ axis position and the velocity is expressed by $V_{x}$ (the velocity of $\mathrm{X}$ axis) and $\mathrm{V}_{\mathrm{y}}$ (the velocity of $\mathrm{Y}$ axis). Modification of the particle position is realized by the position and velocity information. Each particle knows its best value so far $\left(\mathrm{P}_{\text {best }}\right)$ and its $\mathrm{XY}$ position.

This information is analogy of personal experiences of each particle. Moreover, each particle knows the best value so far in the group $\left(\mathrm{g}_{\text {best }}\right)$ among $\left(\mathrm{P}_{\text {best }}\right)$. This information is analogy of knowledge of how the other particles around them have performed. Namely, each particle tries to modify its position using the following information:

- The current positions (x, y),

- The current velocities $\left(\mathrm{V}_{\mathrm{x}}, \mathrm{V}_{\mathrm{y}}\right)$,

- The distance between the current position and $\mathrm{P}_{\text {best }}$

- The distance between the current position and gest
Velocity of each particle can be modified by the following equation:

$$
V_{i}^{k+1}=w V_{i}^{k}+c_{1} * \operatorname{rand}_{1}\left(P_{b e s t, i}^{k}-s_{i}^{k}\right)-c_{2} *
$$$$
\operatorname{rand}_{2}\left(g_{\text {best }, i}^{k}-s_{i}^{k}\right)
$$

where: -

$V_{i}^{k} \quad$ :velocity of particle $\mathrm{i}$ at iteration $\mathrm{k}$

$S_{i}^{k} \quad$ :current position of particle i at iteration k

$p_{\text {best }, i}^{k} \quad$ :personal best of $\mathrm{i}^{\text {th }}$ particle at iteration $\mathrm{k}$

$g_{\text {best }, i}^{k} \quad$ :global best of $\mathrm{i}^{\text {th }}$ particle at iteration $\mathrm{k}$.

$C_{1}, C_{2} \quad$ :social parameters

$w \quad$ :the inertia weight used to accelerate the obtaining of the global best solution in the search space

rand $_{1}$, rand $_{2}$ :a positive random numbers drawn form a uniform distribution between $[0,1]$.

The inertia weighting function is usually utilized in following equation:

$w=\frac{w_{\max }-w_{\min }}{\text { iter }_{\max }} \times$ Iter

where: -

$w_{\max } \quad$ Initial velocity

$w_{\min } \quad$ : Final velocity

iter $_{\text {max }}$ : Maximum iteration number.

Using equation (10), (11) a certain velocity, which gradually get close to $\left(\mathrm{P}_{\text {best }}\right.$ and $\left.\mathrm{g}_{\text {best }}\right)$ can be calculated. the current position and velocity can be modified by the following equation:

$S_{i}^{k+1}=S_{i}^{k}+V_{i}^{k+1}$

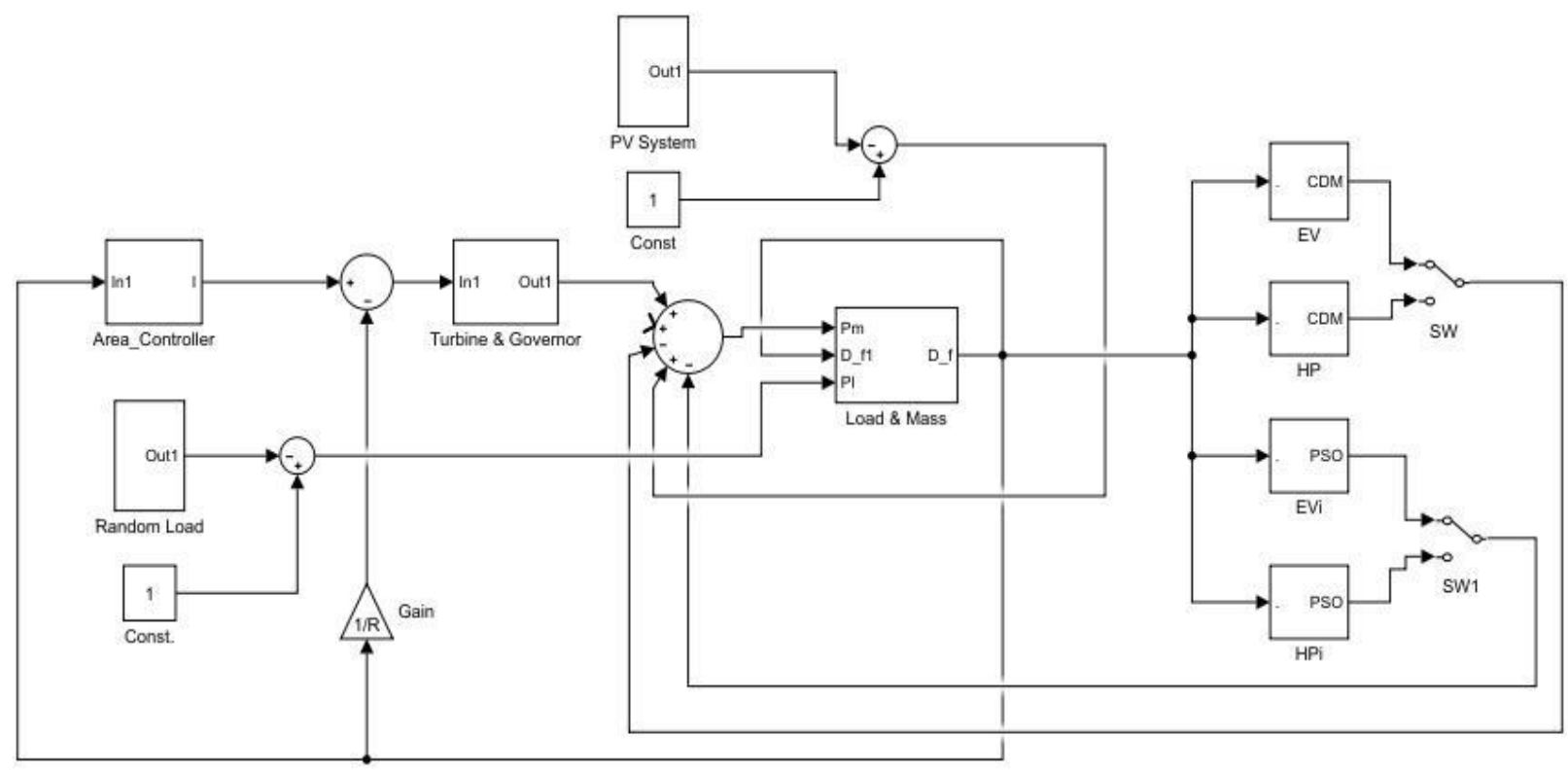

Fig. 4. Overall Simulink of single area power system including the proposed adaptive PSO controller. 
The concept of modification of searching point by PSO is shown in fig. 3.

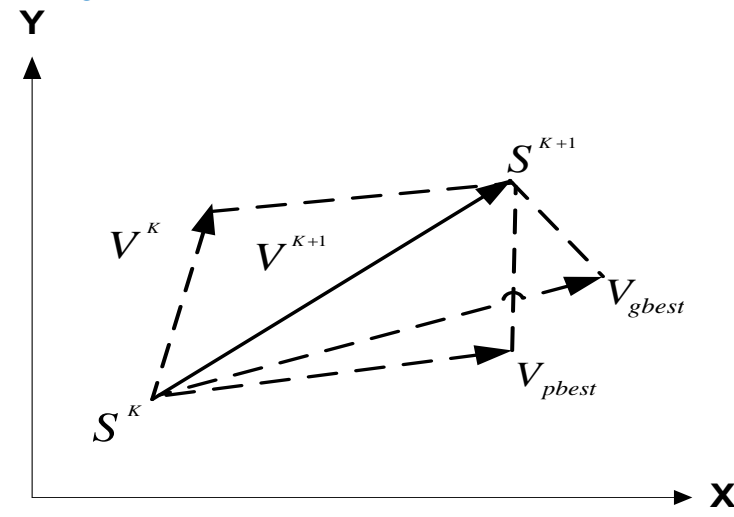

Fig. 3. Modification concept of searching point by PSO.

\section{SYSTEM CONFIGURATION}

The block diagram of a simplified frequency response model for an isolated single area power system including the proposed adaptive (PSO) controller is shown in fig. 4.

The objective of the optimization problem is to minimize maximum overshoot, settling time and rise time as much as possible. The computational flow chart of adaptive PSO algorithm is shown in fig. 5 .

$F_{\text {min }}=\sum M_{p}^{2}+T_{r}^{2}+T_{s}^{2}+E_{s s}^{2}$

where: -

$\begin{array}{ll}F_{\min } & : \text { Objective Cost function } \\ M_{\mathrm{p}} & : \text { Maximum overshoot } \\ T_{r} & : \text { Rise time }(\mathrm{sec}) \\ T_{s} & : \text { Settling time }(\mathrm{sec}) \\ \text { Ess } & : \text { Steady State error. }\end{array}$

The overall system consists of rotating mass and load, non re-heated turbine with GRC and governor with dead band constraints [25]. The frequency deviation is used as feedback for the closed loop control system. On the other hand, additional power sources have been utilized besides diesel generators such as Photovoltaic (PV) and HPs and EVs controllable loads which are modeled as a first order lag systems [26, 27].

\section{RESULTS AND DISCUSSION}

Digital simulations have been carried out in order to validate the effectiveness of the proposed scheme and Matlab/ Simulink package has been used for this purpose. A practical single area microgrid having these data as nominal parameters [2] is considered with the following data: the numerical data for the system are $K i=-0.3, K p=-0.081, T_{t}=0.40 \mathrm{sec}$, $T_{g}=0.10 \mathrm{sec}, D=0.12 \mathrm{pu} / \mathrm{Hz}, M=0.20 \mathrm{pu}$.sec and finally the droop characteristics $(R)=3 \mathrm{~Hz} / \mathrm{pu}$.

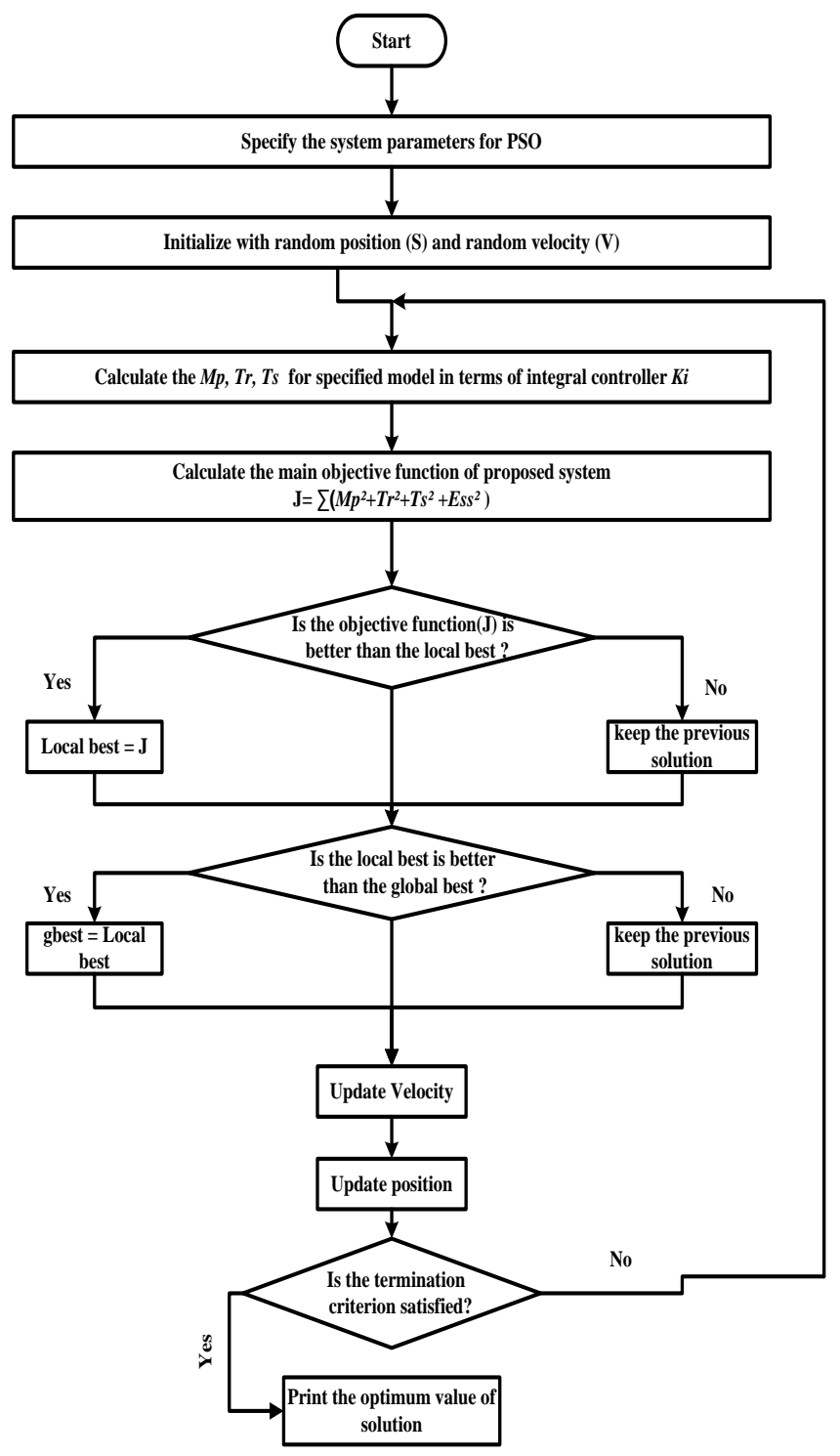

Fig. 5. Flowchart of adaptive PSO

The system performance is tested with the proposed PSO and compared with CDM controller and conventional PI controller at nominal parameters in case of connecting and disconnecting 2 units of EVs and 3 units of HPs controllable loads which listed in Table 1. The specific parameters values for the proposed PSO technique are mentioned in Table 2.

Table 1. Multiple operating conditions of PSO 1 to PSO 5.

\begin{tabular}{lcccc}
\hline Controller & Start & Stop & Start & stop \\
\hline$H P 1$ & $0 s$ & $40 s$ & $70 s$ & $100 s$ \\
$H P 2$ & $30 s$ & $85 s$ & --- & --- \\
$H P 3$ & --- & $20 s$ & $60 s$ & $100 s$ \\
$E V 1$ & --- & $10 s$ & $95 s$ & $100 s$ \\
$E V 2$ & $25 s$ & $50 s$ & --- & --- \\
\hline
\end{tabular}


Table 2. The specific parameters values for the proposed PSO technique

\begin{tabular}{llc}
\hline $\begin{array}{l}\text { Algorithm } \\
\text { technique }\end{array}$ & Parameters & Values \\
\hline \multirow{3}{*}{ Particle Swarm } & Swarm size & 100 \\
Optimization [20] & Max Weight $(w)$ & 200 \\
& Personal iterations & 1.0 \\
& Inertia Coefficient $(C 1)$ & 15 \\
& Inertia Coefficient $(C 2)$ & 2.0 \\
\hline
\end{tabular}

The power of random load and photovoltaic source (PV) in case of load change and fluctuations as shown in fig. 6 .

Figure 7 shows the frequency deviation with adding the controllable loads EVSs and HPs. It has been noticed that the system performance with the proposed adaptive controller tuned by PSO is more stable and fast convergence comparing to CDM and PI controller.

Figure 8 describes the power consumption HPs of the system with suggested adaptive controller compared to the fixed system.

Figure 9 indicates the discharging occurred in the power of EVs by proposed adaptive control scheme. It is clarified that the discharged power of EVs of the suggested controller is less than those of the other fixed controller.

Figure 10 shows the control signal obtained from PSO technique which used as adaptive controller in both HPs and EVs.

Figure 11 describes the power absorbed by diesel $\Delta P_{m}$ with the proposed adaptive controller adjusted by PSO and noticed that it is smaller than with CDM and PI controllers.

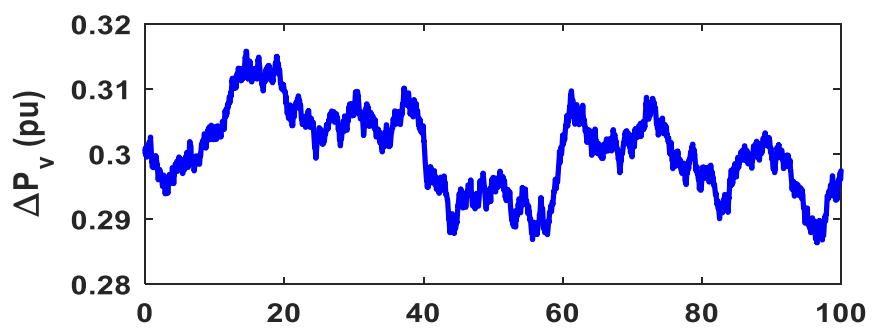

(a)

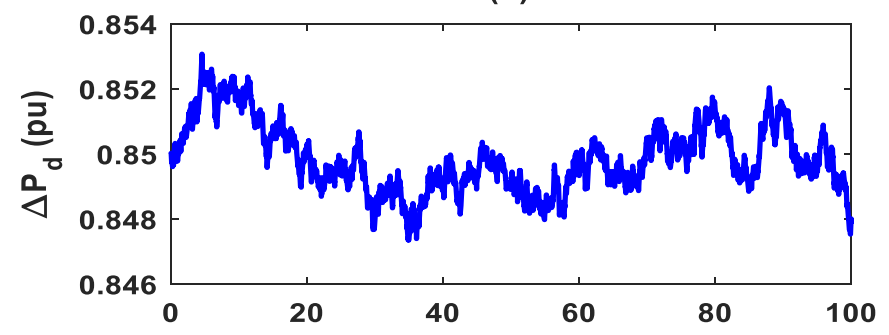

(b)

Time (sec)

(a) PV power. (b) Random Load

Fig. 6. $P V$ and random demand load power change.

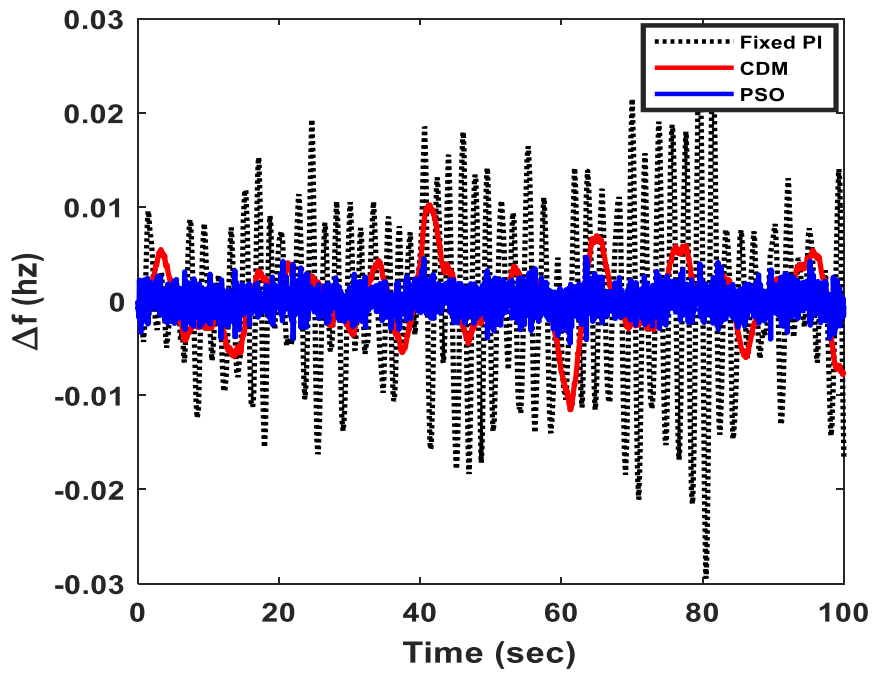

Fig. 7. Power system response of the frequency deviation.

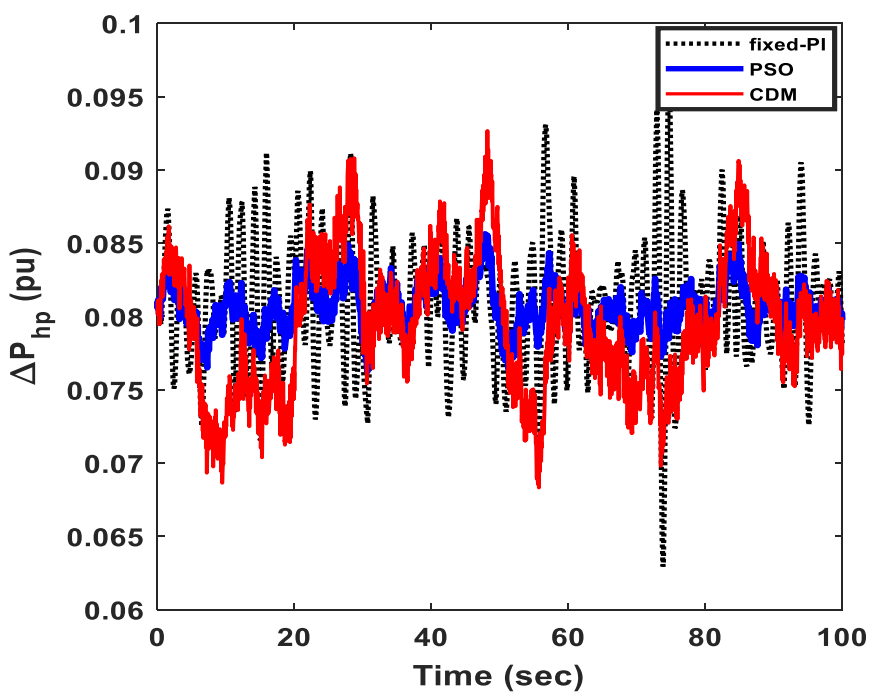

Fig. 8. Heat pump consumption power.

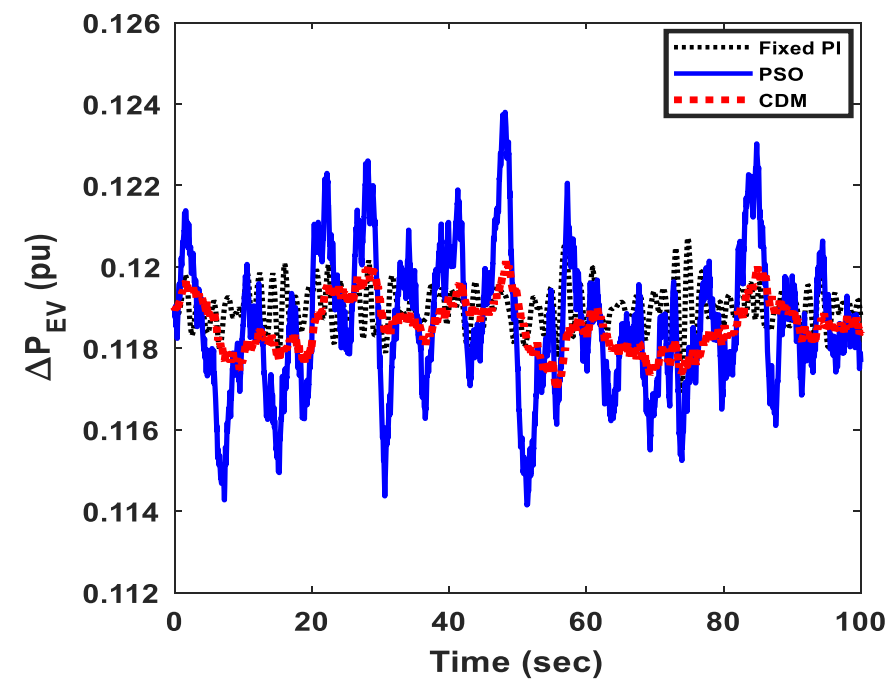

Fig. 9. Electric vehicle discharging power. 


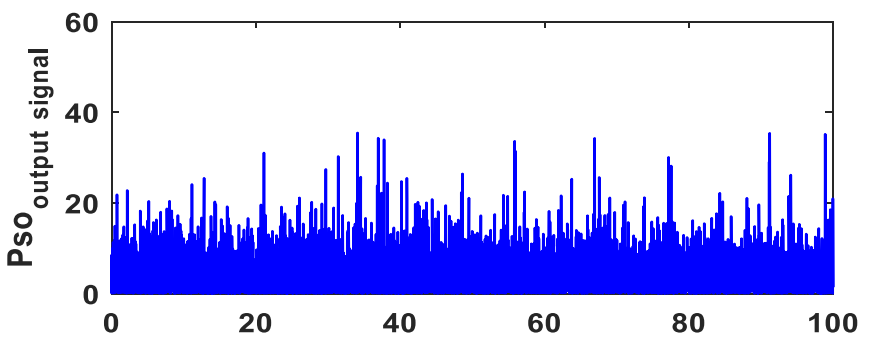

(a)

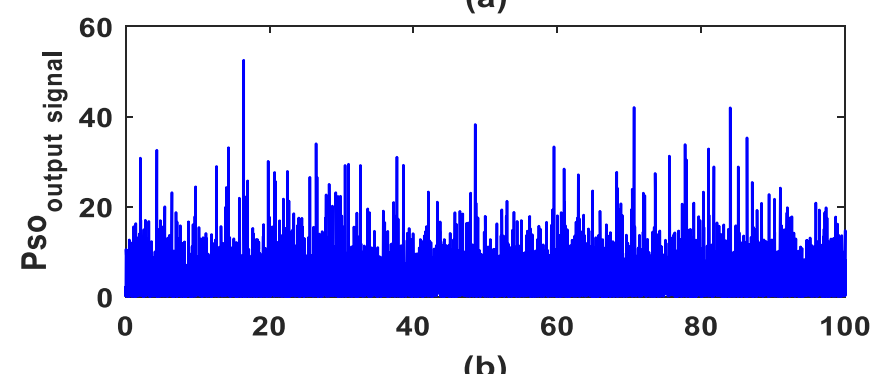

Time (sec)

(a) With HPs. (b) With EVs.

Fig. 10. Control signal of adaptive PSO technique.

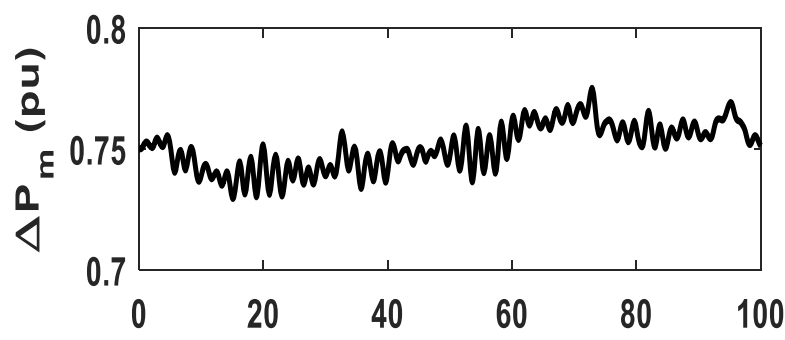

(a)

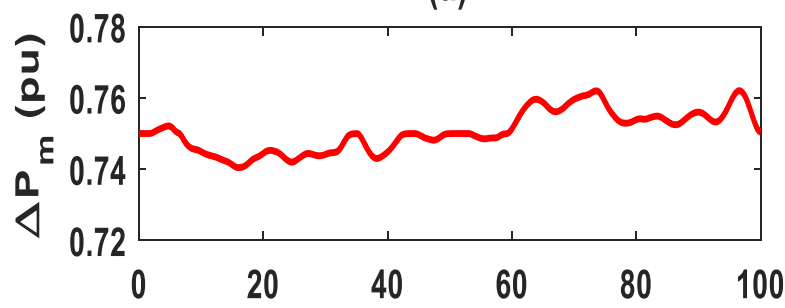

(b)

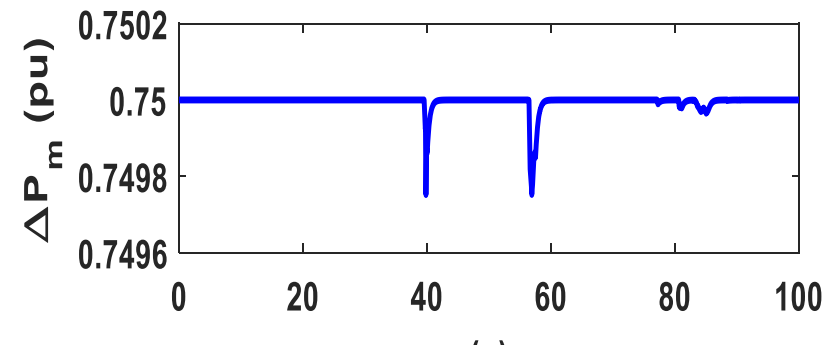

(c)

Time (sec)
Finally, simulation results show that the system response in case of the proposed PSO technique is much better than that of CDM and PI controllers and able to deal with both of random load variations and parameter uncertainty more efficiently besides using the controllable loads EVs and HPs.

\section{CONCLUSION}

A comparative study of performances of PSO and CDM based controllers to a single area load frequency control scheme is carried out in this work. The adaptive PSO controller is seen to perform very well as regards to the frequency and power fluctuations during operation conditions.

The proposed technique showed good performance but highly depends on the choice of its parameters as shown in Table 2. PSO technique gave a very good stable performance of frequency and power responses during large disturbances. A close analysis of the results shows that there is a less overshoot and small settling time in case of the suggested PSO as compared to CDM and conventional PI controllers. So, PSO performs well even when the disturbance is very large and with non-linearity of the power system taken into consideration.

\section{NOMENCLATURE}

$\begin{array}{ll}\Delta f & \text { Frequency deviation (Hz) } \\ \Delta p_{g} & \text { Change in governor output } \\ \Delta p_{m} & \text { Change in diesel mechanical power } \\ \Delta p_{d} & \text { Demand load power change } \\ \Delta p_{c} & \text { Change in speed changer position } \\ \Delta p_{p v} & \text { Power change in photovoltaic } \\ \Delta p_{E V} & \text { Discharging power of hybrid electric vehicle } \\ \Delta p_{H P} & \text { Heat pump consumption power } \\ D & \text { Equivalent damping coefficient }(\mathrm{pu} / \mathrm{Hz}) \\ H & \text { Equivalent inertia constant }(\mathrm{pu} . \mathrm{sec}) \\ \mathrm{R} & \text { Speed regulation parameter }(\mathrm{Hz} / \mathrm{pu}) \\ \mathrm{T}_{\mathrm{g}} & \text { Governor time constant (sec) } \\ \mathrm{T}_{\mathrm{t}} & \text { Turbine time constant (sec) } \\ L F C & \text { Load frequency control } \\ P S O & \text { Particle swarm optimization } \\ C D M & \text { Coefficient diagram method } \\ H P & \text { Heat pump } \\ E V & \text { Electric vehicle }\end{array}$

\section{REFERENCES}

(a) With PI. (b) With CDM. (c) With PSO.

Fig. 11. Change in diesel mechanical power.
[1] Saadat, H., "Power system Analysis", McGraw - Hill Book Company, New York, 1999. 
[2] Kundur, P., "Power System Stability and Control", McGraw - Hill Book Company, New York, 1994.

[3] Aldeen, M. and Marah, J.F., "Decentralized Proportional - Plus-Integral Design Method for Interconnected Power Systems", IEE Proceedings-C, vol. 138, (4), 1991.

[4] Ali M. Yousef, Ayman A. Aly, "Effect of Non-linearities in Fuzzy Approach for Control A Two Area Interconnected Power System", Proceedings of the 2010 IEEE International Conference on Mechatronics and Automation August 4-7, 2010, Xi'an, China .

[5] Yamashika, K., and Miyagi, H., "Multivariable self- Tuning Regulator for Load Frequency Control System with Interaction of Voltage on Load Demand", IEEE Proceedings-D, vol. 138, (2), March 1999.

[6] Aldeen M., "A Fresh Approach to the LQR Problems with Application to Power Systems", Proc. of Int. Power Engineering Conf., Singapore vol. 1,1993 , pp. $374-379$.

[7] Pan, C. I., and Liaw L.M. "AN Adaptive Controller for Power System Load - Frequency Control", IEEE on Power System. vol. 4, (1), pp. $122-128$, Feb. 1989.

[8] V. Shanmuga sundaram, Dr. T. Jayabarathi, "Load Frequency Control using PID Tuned ANN Controller in Power System" 1st International Conference on Electrical Energy Systems (ICEES), 2011, India.

[9] Lokman H. Hassan, Haider A.F. Mohamed, M. Moghavvem, S.S. Yang, "Load Frequency Control of Power Systems with Sugeno Fuzzy Gain Scheduling PID Controller" ICROS-SICE International Joint Conference, 2009, Japan.

[10] Hemeida AM. "Wavelet neural network load frequency controller". Energy Conversion and Management. 1,46(9-10),1613-30, Jun2005

[11] W. Tan, "Unified Tuning of PID Load Frequency Controller for Power Sys-tems via IMC" IEEE Transaction on power systems, vol. 25,(1), Feb. 2010.

[12] Mohammad S.Soheilirad, Mohammad Ali J. Ghasab, Seyedmohammahossein S. "Tuning of PID Controller for Multi Area Load Frequency Control by using Imperialist Competitive Algorithm" Journal of Basic and Applied Scientific Research, vol. 2, (4), pp. 3461-3469, 2012.

[13] M. E-D. Mandour, E. S. Ali, M. E. Lottfy, "Robust Load Frequency Controller Design via Genetic Algorithm and H" Modern Electric Power Systems 2010, Wroclaw, Poland.

[14] E. Salim Ali, S. M. Abd-Elazim, "Optimal PID Tuning for Load Frequency Control using Bacteria Foraging Optimization Algorithm" 14th International Middle East Power Systems Conference (MEPCON'10), 2010, Cairo University, Egypt.
[15] Mohamed AA, Mohamed YS, El-Gaafary AA, Hemeida AM. Optimal power flow using moth swarm algorithm. Electric Power Systems Research. 2017 Jan 1;142:190-206.

[16] Mohamed AA, El-Gaafary AA, Mohamed YS, Hemeida AM. Multiobjective states of matter search algorithm for TCSC-based smart controller design. Electric Power Systems Research. 2016 Nov $1 ; 140: 874-85$.

[17] T. H Mohamed, H. Bevrani, A. A. Hassan, and T. Hiyama, "Mode predictive based load frequency control design," in Proc. 16th International Conference of Electrical Engineering, Busan, Korea, Jul. 2010

[18] Kennedy, J., \& Eberhart, R. "Particle swarm optimization". In Proc. IEEE Int. Conf. Neural Networks, vol. 4. pp. 1942-1948. 1995,Perth: Australia.

[19] Shi, Y., \& Eberhart, R. "Amodified particle swarm optimizer". In Proc. IEEE Int. Conf. Evol. Comput. (pp. 69-73). Anchorage, UK .1998.

[20] Yoshida, H., Kawata, K., \& Fukuyama, Y."A particle swarm optimization for reactive power and voltage control considering voltage security assessment". IEEE Transactions on Power Systems, 2000, 15, pp. $1232-1239$

[21] Ali R, Mohamed TH, Qudaih YS, Mitani Y. "A new load frequency control approach in an isolated small power systems using coefficient diagram method". International Journal of Electrical Power \& Energy Systems. 2014, 56. pp. 110-6.

[22] Mohamed T.H, Shabib G., Abdelhameed E.H, Khamies M., Qudaih Y "Load Frequency Control in Single Area System Using Model Predictive Control and Linear Quadratic Gaussian Techniques". International Journal of Electrical Energy. 3(3). Sep, 2015

[23] Manabe S. "Coefficient diagram method". In: 14th IFAC symp on automatic control in aerospace, Seoul; 1998

[24] EL-Zonkoly, A.M..,"Optimal tuning of power systems stabilizers and AVR gains using particle swarm optimization". International Journal of Expert Systems with Applications, 2006, vol. 31(939). pp. 551-557.

[25] H. Bevrani," Robust power system frequency control". vol. 85 . pp.15-61. New York: Springer, 2009.

[26] Xu Hao, Miao Shihong, Zhang Chunyong, Shi Dongyuan. "Optimal placement of charging infrastructures for large-scale integration of pure electric vehicles into grid". Int J Electr Power Energy Syst (IJEPES)., 53. pp.159-65, 2013.

[27] Senjyu T, Tokudome M, Yona A, Funabashi T. "A frequency control approach by decentralized generators and controllable loads in small power systems". IEEJ Trans Power energy , 9 . pp.1074-80.2009. 